\title{
Seele des Dienstes
}

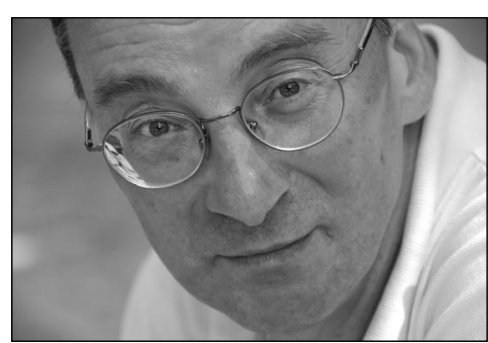

Foto: Petra Schmucker, Frankfurt am Main
Auch der Großstädter wohne nie in einer großen Stadt, sondern in irgendeinem Dörfchen innerhalb von New York, London, Paris, Berlin, stellte der deutsche Schriftsteller Ludwig Marcuse im vorigen Jahrhundert fest. Der Stadtteil, der Bezirk, der Kiez sind für viele Menschen auch heute noch der Orientierungsrahmen im Alltag. Das gilt auch für die soziale Versorgung und soziale Dienste und Einrichtungen tun deshalb gut daran, sich entsprechend zu orientieren. Herbert Schubert vom Forschungsschwerpunkt »Sozial I Raum | Management « der Fachhochschule Köln beschreibt in seinem Beitrag in diesem Heft, worauf die dabei beteiligten Personen, Gruppen und Institutionen achten müssen. Von hohem Wert sei die sozialräumliche Arbeit insbesondere für die Sozialwirtschaft, da Kompetenzen und Wissen der Ressorts, die an Prozessen zur Unterstützung der Adressaten beteiligt sind, an verschiedenen Orten in Netzwerken zielgesteuert und flexibel verbunden werden könnten. Wolf Rainer Wendt erinnert in seinem Beitrag daran, den Sozialraum nicht allein institutionell zu definieren. Der Blick der Profis müsse sich auch auf die informelle und selbstorganisierte Versorgung der Menschen richten. Es gehe um Passgenauigkeit von Diensten für Bürger und um ihre Eigenaktivität, Selbstbestimmung und Teilhabe. Darauf solle sich die sozialwirtschaftliche Steuerung, solle sich das Management der zu leistenden Arbeit beziehen. Gelingen kann dieser Spagat zwischen den Welten der Organisationen und dem Alltag der Menschen letztlich nur bei einem genauen Wissen über den jeweiligen Sozialraum. "Kenntnis des Ortes ist die Seele des Dienstes", mahnte Freiherr vom und zum Stein bereits im alten Preußen.
Gerhard Pfannendörfer - Chefredaktion -

\section{Sozialmanagement aktuell}

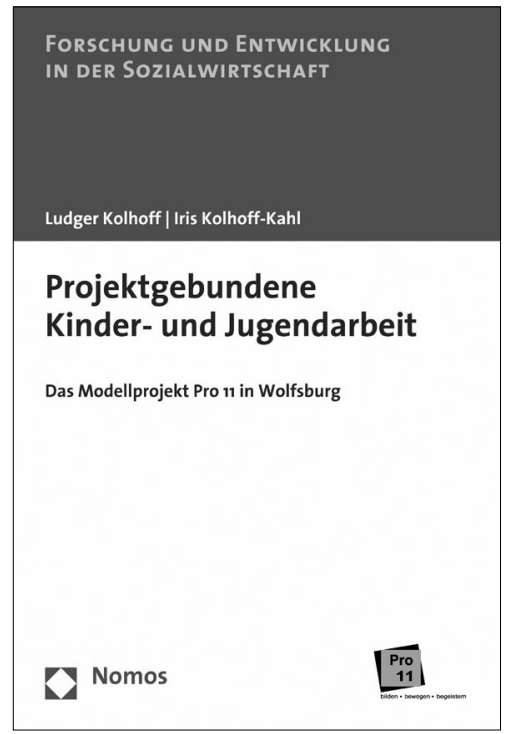

Projektgebundene Kinderund Jugendarbeit

Das Modellprojekt Pro 11 in Wolfsburg

Von Prof. Dr. Ludger Kolhoff und

Prof. Dr. Iris Kolhoff-Kahl

2009, 135 S., brosch., 24,- $€$,

ISBN 978-3-8329-3733-1

(Forschung und Entwicklung

in der Sozialwirtschaft, Bd. 5)

Die offene Kinder- und Jugendarbeit "Pro 11« in Wolfsburg wurde von einem Organisationsentwicklungsprozess begleitet. Der Band analysiert und interpretiert den gesamten Prozess und stellt positive wie negative Erfahrungen vor. Es wird gezeigt, wie Theoriekonzepte und Praxisumsetzungen wiederum neue überraschende Handlungs- und Denkoptionen eröffnen. Ein Buch für alle, die sich mit Sozialmanagement befassen.

\section{Nomos}

Bitte bestellen Sie im Buchhandel oder versandkostenfrei unter www.nomos-shop.de 